\title{
Confidence Frames and the Mastery of New Challenges in the Motivation of an Expert Skydiver
}

\author{
John H. Kerr \\ University of British Columbia \\ Susan Houge Mackenzie \\ California State Polytechnic University
}

\begin{abstract}
The main objective was to further unravel the experience of motivation in an expert male skydiver by investigating: (1) his general experience of motivation and perception of the dangers of skydiving; (2) his pursuit of new challenges and learning new skills as factors in maintaining motivation; (3) evidence of a mastery-based confidence frame in his motivational experience. This was a unique case study informed by reversal theory. The participant's perception of skydiving was that it was not a risky or dangerous activity and a primary motive for his involvement in skydiving was personal goal achievement. Maintaining control and mastery during skydiving was a key motivational element during his long career and pursuing new challenges and learning new skills was found to be important for his continued participation. Data indicated that his confidence frame was based on a telic-mastery state combination, which challenged previous reversal theory research findings and constructs.
\end{abstract}

Keywords: expert skydiving, adventure sports, confidence frames, new challenges, case study, reversal theory

The results of psychological research on participant motivation in adventure sports have indicated that participation motives include, but are not limited to: Goal achievement (Willig, 2008), social relationships (Kerr \& Houge Mackenzie, 2012), risk-taking or sensation seeking (Chirivella \& Martinez, 1994; Rowland, Franken, \& Harrison, 1986), alleviating boredom (Kerr \& Houge Mackenzie, 2012), pushing personal boundaries and overcoming fear (Allman, Mittelstaedt, Martin, \& Goldenberg, 2009; Brymer \& Oades, 2009), connecting with nature (Brymer, Downey, \& Gray 2010; Varley, 2011), pleasurable kinesthetic bodily sensations from moving in water or air (Varley, 2011), and control, mastery and skill (Allman, Mittelstaedt, Martin, \& Goldenberg, 2009; Willig, 2001). Sport parachute jumping or skydiving, is an adventure sport that has been the subject of psychological research on participant motivation (e.g., Hymbaugh, \& Garrett, 1974; Thatcher, Reeves, Dorling, \& Palmer, 2003). During skydiving participants travel in airplanes up to a height of $3-4500 \mathrm{~m}$ and, when at

Kerr is with the Dept. of Kinesiology, Univeristy of British Columbia, Vancouver, BC. Houge Mackenzie is with the Dept. of Recreation, Parks, and Tourism Administration, California State Polytechnic University, San Luis Obispo, CA. Address author correspondence to John H. Kerr at johnkerrsportpsych@ gmail.com. the desired height, they exit the plane and go into "free fall" for periods of up to a minute before releasing their main "canopy" (parachute). During free fall, skydivers may attempt forward or backward acrobatic maneuvers as they reach velocities that can exceed $160 \mathrm{kph}$ during their free fall descent (Lipscombe, 1999). Skydivers also have a reserve canopy that they can use if the main canopy malfunctions.

Researchers have identified a range of motives for skydiving. For example, Apter and Batler (1997) asked male and female sport parachutists to respond to a list of motivational items. The list consisted of ten items and respondents $(n=61)$ could indicate as many motivational items as they wished. The results showed that all ten items were endorsed by the participants. These are listed here in order of response frequency with the number of citations in parenthesis following each item: excitement or thrill (56); immediate fun (51); serious achievement (45); control and mastery (42); being part of a community or group (42); helping others master the situation (22); defying convention (19); relief afterward (15); being concerned for others (10); and being a center of concerned attention (6). Several of these motives overlap with the participation motives described earlier for adventure sports in general (e.g., "risk taking or sensation seeking"; "goal achievement", "control mastery and skill"; "social relationships"). The results of the Apter and Batler (1997) study suggested that participant motivations in 
sport parachuting are diverse and often include multiple participation motives. These findings have been supported by more recent research with a broader range of adventure sport participants who described their fundamental motivations as multifaceted (Kerr \& Houge Mackenzie, 2012). Although the individuals in Kerr and Houge Mackenzie's study sometimes reported the same participation motives, they also differed in order of importance attached to each one.

While adventure sport athletes generally, and sport parachutists in particular, tend to perceive their basic motives in broad motivational categories (Apter \& Batler, 1997) this approach does not provide fine-grained insights into the dynamic nature of motivation in adventure sports. For example, research has not fully explained how motives can change with on-going engagement in adventure sports, or how interest and motivation can be maintained through the acceptance of regularly renewed challenges. With respect to taking on new challenges, Willig (2008) found that adventure sport participants generally had a good knowledge of their own and other participants' abilities and, as they acquired increasing levels of skill and experience, recognized their own progress. This was experienced as a rewarding sense of mastery. In addition, participants carefully appraised the challenges involved in undertaking new activities or skills in their sports and only took on challenges that were within their capabilities (Willig, 2008).

These findings are supported by flow and reversal theory research that demonstrated the importance of increasing challenges to facilitate flow, in the short term, and longer term engagement in adventure activities (Houge Mackenzie, Hodge \& Boyes, 2011). These authors also found support for a dynamic tensions model of engagement wherein opposing states with varying challenge levels contributed to longer term engagement in adventure activities. They concluded that adventure participant motives (1) regularly reversed between playful and serious motives and (2) progressed from sensation seeking to serious/mastery and social motives over time (Houge Mackenzie, Hodge \& Boyes, 2013). The present study further investigates these findings by examining the experience of mastery and the motivational processes involved in taking on new challenges in skydiving.

\section{Reversal Theory Findings \& Constructs}

The motivational constructs used in the parachuting study (Apter \& Batler, 1997) and adventure sports studies (Houge Mackenzie et al., 2011, 2013) described above were informed by reversal theory (e.g., Apter, 1982, 2001) and represented the diverse basic motives outlined in the theory. Reversal theory-based research has been used to understand and explain motivation in a number of previous research studies on different adventure sport activities (Chirivella \& Martinez, 1994; Cogan \& Brown, 1999; Florenthal \& Shoham, 2001; Kerr, 1991; Kerr \& Houge
Mackenzie, 2012; Kerr \& Svebak, 1989; Legrand \& Apter 2004; Pain \& Kerr, 2004; Trimpop, Kirkcaldy, \& Kerr, 1998). However, in spite of reversal theory-based research findings that participation motivation is multifaceted (e.g., Apter \& Batler, 1997), the majority of these studies have focused on the arousal-seeking, excitement and thrill aspects of adventure activities, thus overlooking other important motivational categories. This may have resulted in undue emphasis on paratelic-oriented motivations for adventure sport and other risky activities in much of the reversal theory thinking and literature (e.g., Apter, 1992). These conclusions are supported by recent nonreversaltheory-based findings that highlight alternative motives for adventure sport, such as interacting with the natural environment or emotional regulation (e.g., Brymer \& Gray, 2010). These studies also found that adventure participation may induce life transformations and strong relationships with the natural world (Brymer, 2009).

As reversal theory is the guiding framework in the current study, a brief explanation of reversal theory follows. According to reversal theory, individuals switch, or reverse, between paired mental or metamotivational states producing significant changes in their motivational and emotional experience. These states govern the way a person interprets his or her motives at a certain time. There are four pairs of opposing states, and each state has its own characteristics. A person in the telic state tends to be primarily serious, goal-oriented, and arousal avoiding, and spontaneous, playful, and arousal seeking in the paratelic state. In the conformist state, a person is compliant and agreeable, and rebellious, unconventional, and defiant in the negativistic state. A person in the mastery state tends to be competitive and dominating, and has a desire for harmony and unity, and tries to be cooperative in the sympathy state. In the autic state, a person is egoistic, and altruistic and concerned with others in the alloic state. Reversals are caused by environmental stimuli (e.g., a mountain biker, whose closest rival in a race crashes, injures himself and has to retire from the competition, reverses from the mastery to the sympathy state) frustration (e.g., a downhill skier, perceiving herself to have been wrongly disqualified from a race, reverses from the conformist to the negativistic state), or satiation (a canoeist reaches her destination after a difficult ocean trip, and reverses from the telic to the paratelic state). Reversal theory also posits that there are sixteen somatic and transactional primary emotions that result from different combinations of metamotivational states. These are: Relaxation, excitement, placidity, provocativeness, pride, modesty, gratitude, virtue, anxiety, boredom, anger, sullenness, humiliation, shame, resentment, and guilt (see Table 1).

A crucial reversal theory concept in understanding motivation in adventure sports is that of phenomenological protective frames (Apter, 1992, 1993). Three different types of protective frames have been proposed: These are the confidence frame, the safety-zone frame and the detachment frame. Protective frames are cognitivelybased, subjectively-determined and in conjunction with 
Table 1 Metamotivational State Combinations and the 16 Primary Emotions

\begin{tabular}{|c|c|c|}
\hline \multicolumn{3}{|c|}{ Somatic Emotions } \\
\hline State combination & Pleasant & Unpleasant \\
\hline telic-conformity & relaxation & anxiety \\
\hline telic-negativism & placidity & anger \\
\hline paratelic-conformity & excitement & boredom \\
\hline paratelic-negativism & provocativeness & sullenness \\
\hline \multicolumn{3}{|c|}{ Transactional Emotions } \\
\hline State combination & Pleasant & Unpleasant \\
\hline autic-mastery & pride & humiliation \\
\hline autic-sympathy & gratitude & resentment \\
\hline alloic-mastery & modesty & shame \\
\hline alloic-sympathy & virtue & guilt \\
\hline
\end{tabular}

operative metamotivational states influence how a person interprets his or her current experience. A protective confidence frame, associated with the paratelic state, forms a kind of 'psychological bubble' around a dangerous activity allowing the participant to cope with risks and enjoy high arousal as excitement. Therefore, the confidence frame is important in the context of adventure sports as it allows participants to approach their sport with a reduced sense of danger and an increased sense of safety arising from, for example, confidence in their own abilities, the abilities of others, or the use of 'safe' technologically-advanced equipment. Confidence frames may fail either temporarily, or over the longer term, if an adventure participant's subjective appraisal of the risks involved changes. This was illustrated by the case of an accomplished female skydiver discussed by Kerr (2007). "Julie" suddenly withdrew from skydiving when her friend died in a skydiving accident. As well as withdrawing from skydiving, she became severely anxious and depressed, was unable to continue working, and even contemplated suicide. The death of Julie's friend changed her perception of the risks in skydiving destroyed her confidence frame, and had a major impact on her life beyond skydiving. Recent studies of adventure tourism guides have further demonstrated the utility of this concept in understanding adventure tourism guiding, and the negative effects of removing or failing to establish protective frames in adventure activities (Houge Mackenzie \& Kerr, 2012).

Apter (1992) outlined the importance of paratelic (playful) motivation for maintaining the confidence frame in dangerous situations. Confidence frames can only occur under conditions of perceived control and security, which are generally familiar and predictable for the individual involved. Therefore, the high arousal paratelic experience in risky or dangerous activities is 'planned' arousal in a subjectively controlled situation (Trimpop, 1994). While control and mastery are crucial to confidence frames, the possible role of the mastery state has received less attention than the paratelic state in reversal theory literature. However, recent evidence from adventure sports has indicated that the confidence frame is also closely allied with mastery motivation (Houge Mackenzie \& Kerr, 2012; Kerr \& Houge Mackenzie, 2012). Furthermore Males (2013) argued that the confidence frame is a function of the mastery state and that, contrary to extant literature, it can coexist with either the telic or paratelic state to create effective performance in elite-level competitive sport. While Males' (2013) work extended previous reversal theory thinking about the nature of protective confidence frames, additional research is required to establish whether his findings can be replicated in the context of adventure sports. Thus, this was one of the aims of the current study.

\section{The Present Case Study}

Case study research is now well established in the psychology and sport psychology literature. For example, The Sport Psychologist recently dedicated a complete issue to case studies (Hanton, 2012). Single case studies are worth documenting when the investigator has access to a previously inaccessible or unique situation and/or the case can be used to confirm, challenge, or extend an established theory (Bromley, 1986; Yin, 1994). The present single case study focused on an elite skydiver and was considered unique because the skydiver had such a vast experience across recreational, competitive, and professional (i.e., as an occupation) skydiving (see Case Description and Context section below). He had completed over 20,000 jumps at the time of his interview and was able to describe the development of his motivation over time and across contexts with the knowledge gained from over 20 years of experience.

Qualitative interview methods were used and reversal theory constructs (e.g., Apter, 1982, 2001) informed the analysis of case material. The main purpose of the case study was to further unravel the experience of motivation in the adventure sport of skydiving. In particular, the researchers' aims were to investigate: (1) the participants' general experience of skydiving, with a focus on motivation and risk perception; (2) if accepting renewed challenges and learning new skills were factors in maintaining the participant's motivation over time; (3) the possibility of a mastery-based confidence frame in the skydiver's motivational experience. The current case study was thought to be a unique case that could contribute to current knowledge about the experience of motivation in skydiving, with additional potential for challenging and extending reversal theory conceptualizations (Bromley, 1986; Yin, 1994).

\section{Method}

The present case study emerged from qualitative data collected as part of a larger study of motivation and experience in adventure sport activities which used theory-based purposeful sampling (Houge, 2009). Initial 
contact with potential participants was made via telephone or e-mail. Those who agreed to participate were then mailed an information sheet detailing the research topic (i.e., motivations and emotions experienced during adventure sports), the data collection process, and an informed consent form. The study had received prior ethical approval from the relevant university committee.

\section{Sampling Procedures}

Theory-based purposeful sampling guidelines indicate that individuals with the most experience and knowledge of an activity or phenomenon can provide the most information-rich case studies (e.g., Patton, 2002). In addition, athletes with greater levels of experience and proficiency have a larger experiential reference base to draw upon and may be better able to articulate key psychological states experienced during sport (e.g., Jackson, 1996). A population that met these requirements was expert adventure instructors. There were a number of additional reasons that this sample (which included the participant in the present case study) was considered appropriate. First, the requisite certification processes to become an instructor in adventure activities demand compliance with rigorous industry measures of proficiency and field experience. For example, the New Zealand Parachute Industry Association (NZPIA) certification process sets skydiving proficiency standards (e.g., the minimum number of logged jumps for tandem instructors) that are aligned with the international sport licensing body, Federation Aeronautique Internationale (FAI). Based on standardized industry-wide assessment documents (e.g., written examinations and official instructor logs, which detail and evaluate each trip) it was possible to judge whether an adventure practitioner was an expert and to accurately gauge his/her experience level. A further benefit of interviewing instructors was the likelihood that they would have reflected upon their adventure experiences (e.g., via debriefings with employers/clients/peers and self-evaluation logs) more than purely recreational participants. In this manner, the participants in the larger study were theoretically sampled based on their depth and breadth of adventure sport experience using a snowballing method (Patton, 2002). This sampling procedure ensured that highly accomplished and experienced adventure professionals (based on industry achievements and certifications) were recruited, and that the sample consisted of participants previously unknown to the interviewer.

\section{Case Description and Context}

The participant in this case study, Vlad (a pseudonym), was a 37-year-old with 21 years of experience as a sport parachutist, paratrooper, international skydiving competitor, and skydiving instructor. At 16 years of age, he embarked on an introductory skydiving course at the local sport parachute club in his town. Vlad was required to complete four and a half months of ground training before being allowed to jump using a static line, which opens the parachute automatically after leaving the plane. (The use of a static line minimizes the risk of malfunctions, but eliminates the free fall portion of a jump.) He quickly progressed to free fall skydiving and became involved in local competitions and formation skydives before eventually progressing to the national team and representing his country at the World Championship level.

During this time, Vlad was called into military service as a paratrooper, which then consisted of low altitude jumps with round canopies and no free fall. Vlad felt these military jumps boring: ". . . you know, for someone who is doing a first jump they would be great fun, but once you pass that stage and you [have] got a few 100 jumps you can't go back to static line jumps - they are too boring." This experience contrasts with modern skydiving techniques where developments in training and equipment allow a beginner to skydive with a tandem instructor connected to him/her by a harness after $30 \mathrm{~min}$ of instruction. (Tandem skydives involve free falling for 30-60 s before the canopy is opened, with a further five minute descent before landing.) Upon leaving the military, Vlad decided to make a career out of skydiving by becoming a tandem instructor. In addition to this commercial instruction, he became an examiner of other tandem instructors and the operations manager for one of the world's busiest tandem skydiving companies. Rather than view his vocation as a career, Vlad was emphatic that for him skydiving was a lifestyle choice (Wheaton, 2004): "When you are a skydiver, your whole life revolves around skydiving. Someone who is engaged in ... skydiving ... you become a skydiver ... that's the way you live your life."

\section{Study Design and Procedures}

The Scanlan Collaborative Interview Method (SCIM; Scanlan, Russell, Wilson, \& Scanlan, 2003) was used in conjunction with the reversal theory-based Metamotivational State Coding Schedule (MSCS; O'Connell, Potocky, Cook, \& Gerkovich, 1991) to direct the inductive-deductive interview procedure throughout the larger research study (Kerr \& Houge Mackenzie, 2012). The SCIM methodology allows researchers to ask openended inductive questions in the first part of the interview, followed by predetermined deductive questions at the end of the interview. It culminates with the creation of a participant's "picture" of experience that incorporates inductive and deductive concepts and allows for preliminary member checking at the end of the interview. Both the SCIM procedure and the MSCS instrument have been successfully used in previous qualitative sport psychology research (SCIM-e.g., Scanlan, Russell, Beals, \& Scanlan, 2003; MSCS — e.g., Males, Kerr \& Gerkovich, 1998). The inductive-deductive interview method allowed for emergent concepts as well as possible confirmation and/or expansion of established reversal theory concepts.

This collaborative interview technique afforded personal depth and detail as well as scholarly rigor. In this format, the interviewer and participant worked in tandem to literally create an individualized picture of 
the participant's experience (Scanlan, Russell, Wilson et al., 2003). The interview process was characterized by an ambience of partnership, highlighted by the sideby-side positioning of the researcher and participant as recommended by Scanlan, Russell, Wilson et al. (2003). This unique spatial arrangement was accompanied by clear, detailed explanations of the voluntary nature of the interview and its structure, process and purpose.

The SCIM was selected due to its multilevel approach to data analysis which clearly delineated potentially theory-expanding data (i.e., participant-derived "inductively" grounded data) from theory-confirming data (i.e., theory-derived "deductive" data), and areas of overlap between these data sources (Scanlan, Russell, Wilson et al., 2003). The advantage of this method was that it created a checklist and framework for qualitative analysis. Any theorized constructs were assessed with regard to their temporal occurrence and reported significance to the focal concept. Confirmation or nonconfirmation of key concepts was identified along with their perceived impact on the phenomenon of interest. Scanlan, Russell, Wilson et al. (2003) contended that this focused analysis of content could reveal underlying mechanisms while still including emergent, idiosyncratic information, regardless of whether it was theory-confirming.

Versions of the SCIM have been used successfully to test and expand the Sport Commitment Model (Scanlan, Russell, Beals, \& Scanlan, 2003) and to generate constructs of Athletic Engagement (Lonsdale, Hodge, \& Raedeke, 2007) among elite athletes. Moreover, participants (e.g., members of the New Zealand All Blacks and Silver Ferns national teams) had highlighted the ecological validity and success of the SCIM's collaborative process. In previous studies, athletes responded positively to the creation of a personalized theoretical diagram during the interview; "It's given me in words and in a picture just who I am and what my capabilities are and what I can achieve" (Scanlan, Russell, Beals et al., 2003, p. 375). These affirming sentiments strengthened the rationale for utilizing the SCIM as participants reported personally meaningful experiences during the research process.

\section{Interview Structure}

The current case study was based on a 129 min audiorecorded, in-depth interview conducted in Vlad's home without distractions. The SCIM was conducted in four parts.

Part 1. The interview began with a discussion of Vlad's background with regard to skydiving to build the foundation for a collaborative relationship. The interview format was then outlined so that any questions regarding the nature or process of the inquiry could be answered. The interviewer introduced the focal concept as the emotions and motivations experienced during skydiving. This "bounded" the specific topic area, focused the discussion, and provided a clear understanding of the topic of interest without suggesting any of the particular emotions, motives, or theoretical constructs (Scanlan, Russell, Wilson et al., 2003). This was important, as the initial inductive approach was designed to elicit candid reports of idiosyncratic experiences.

Part 2. In the second phase, Vlad was asked to describe thoughts and feelings he remembered before, during, and following different skydiving experience(s; Lonsdale et al., 2007). This temporal division of adventure experiences had been shown to demarcate diverse mental strategies and frames of mind among adventure sport participants (e.g., Burke \& Orlick, 2003; Males, 1999). Furthermore, it facilitated data analysis later on by allowing the identification of reversal theory coding units. Coding units are defined in reversal theory as distinct periods of time in which the participant reports a single goal and experiences only one combination of metamotivational states (e.g., Males, 1999; Potocky et al., 1991).

Open-ended questions, such as "Could you describe your first/most memorable/most significant/recent skydiving experiences?"; "Could you tell me about this experience as though you were telling me a story?"; and "What were your thoughts and feelings before/during/ after this experience?" were designed to elicit inductive accounts of the motivational and emotional dynamics involved in skydiving. As Vlad reported on his varied experiences, he was probed for information regarding similarities or differences across experiences, and any internal or external factors that may have influenced or instigated changes in his emotions, thoughts, or motivations before, during, and after skydiving. For example: "What motivated you before/during this experience?"; "How did you feel at this point in the experience?"; or "Could you describe anything that influenced this experience (either positively or negatively)?"

While Vlad recalled his experiences, the interviewer recorded raw data descriptors on yellow "Post-it" cards that summarized his descriptions and then displayed these on the table (Hinsdale et al., 2007). Once an exhaustive set of raw descriptors was generated, Vlad and the interviewer worked collaboratively to create inductive dimension "themes" to form a preliminary 'picture' of his skydiving experiences (Hinsdale et al., 2007)

Parts 3 and 4. In the third section, comprised of deductive questions, the interviewer stated that she would now present some motives and emotions that had previously been reported by some adventure sport participants, but that they might or might not apply to Vlad's experiences. Vlad was assured that the interviewer was only interested in his personal experiences, regardless of whether they included the concepts she was about to introduce. Preprepared blue index cards with the following "potential" emotions and motivations derived from reversal theory literature were then presented: Serious-minded; light-hearted; playful; spontaneous; bored; excited; calm; anxious; worried; relaxed; cautious; adventurous; having fun; 
"reversal" (accompanied by a description of this term: sudden change in the way you felt or how you viewed your situation). The statements below, derived from reversal theory literature (e.g., the MSCS; O'Connell et al., 1991), were also presented on separate blue cards:

1. I wanted to accomplish something-I had a goal

2. I was in the moment

3. Focused on the future/Planning ahead

4. Concerned about consequences of my current activity

5. Unconcerned about consequences of my current activity

6. More aroused/emotionally intense/"worked up" than in everyday life

7. Less aroused/emotionally intense/"worked up" than in everyday life

8. I wanted to feel more aroused

9. I wanted to feel less aroused

10. I wanted to have peace and quiet

11. I wanted to feel a "buzz" or seek thrills

12. The sensation of the activity itself was enjoyable

13. I wanted to avoid obstacles/challenges/risks

\section{I wanted to seek out challenges/risk}

As each index card was placed on the table, Vlad had the opportunity to (a) confirm that the dimension was already included in his inductive picture comprised of yellow cards, (b) add the dimension (in its original or a modified form) anywhere in his picture, or (c) reject the potential dimension if it was not a part his experience (Lonsdale et al., 2007). Following this presentation of theory-derived dimensions of experience, the fourth section provided an opportunity for Vlad to give feedback on the interview process and make adjustments and clarifications regarding his personal picture of skydiving experiences. His final diagram was digitally photographed and the interview was digitally recorded.

\section{Data Analysis}

Data analysis began with the researcher immersing herself in the interview data. While transcribing the interview, she familiarized herself with the audio recording, verbatim data transcript, and photographic data of the diagram created during the interview. These data sources were perused for the emergence of key motivations, emotions, and patterns of experience, as well as for key reversal theory themes (operative metamotivational states, reversals, emotions experienced, and the possible presence and nature of protective confidence frames; Houge, 2009). Evidence of reversal theory constructs were identified through the use of existing coding instruments (Metamotivational State Interview (MSI) and Metamotivational State Coding Scale (MSCS; Males et al., 1998; O'Connell et al., 1991; Potocky et al., 1991). Raw data quotes were color-coded and grouped into related themes in an extensive 15 page PowerPoint summary document that first outlined the major emotional and motivational themes along with supporting quotes, and then diagrammed each experience sequentially with supporting inductive and deductive interview data linking it to the main themes. Inductive versus deductive data were delineated via a color-coding system as evidence for a reversal theory theme was considered stronger when supported by inductive and deductive data. This also allowed for assessment of convergence or divergence between inductive and deductive data, a suggested requirement when analyzing SCIM data (e.g., Scanlan, Russell, Wilson et al., 2003).

\section{Trustworthiness}

In qualitative research, the quality of data collected is dependent on the extent to which the investigator can establish sufficient credibility and trustworthiness, rather than reliability and validity (e.g., Krane, Andersen, \& Strean, 1997). In the current study the aim was to ensure that interviewer guarded against any subjective bias that might have influenced the data collection and analysis process. A "thick description" of the sampling and interview procedures was reported in sufficient detail to allow others to evaluate their credibility (e.g., Patton, 2002). In addition, the completion of member checking, triangulation, and an audit trail contributed to the trustworthiness of the data (Denzin \& Lincoln, 2000). The audit was carried out by a respected university academic who was well-versed in both reversal theory and adventure sports. Before this point, the auditor had not been not involved in content analysis (Denzin \& Lincoln, 2000; Gratton \& Jones, 2004). The auditor first reviewed all verbatim transcripts, pictures, and member checks to identify common themes. The auditor then compared his analysis to the researcher's analyses. Minor discrepancies or inconsistencies were discussed and reconciled as recommended, for example, when using the MSCS to code participant responses (O'Connell et al., 1991). No major omissions or misrepresentations of the data were reported by the auditor (Houge, 2009).

Specifically with regard to Vlad's interview, any unclear statements within the interview were addressed verbally in part four of the SCIM interview procedure, and in the follow-up member checking process wherein Vlad was given the opportunity to modify or elaborate upon statements included in the 15 page PowerPoint summary document described above (e.g., Denzin \& Lincoln, 2005; Richardson, 1996). After reading the document, Vlad reported that he did not identify any misrepresentations of the data, and that he enjoyed the interview process and final document.

Finally, in preparing the present case study, all the procedures described above (sampling, interview procedures, member check, triangulation, and audit trail), as well as Vlad's interview material, were carefully reviewed again by a third person, also an expert on both reversal theory and sport, with previous experience in qualitative 
research, including research on adventure sports. This additional researcher confirmed the appropriateness of the steps taken in the research and the accuracy of the subsequent data analysis and reversal theory interpretation.

\section{Results and Discussion}

To better illustrate key findings and implications from this case study, the results and discussion sections of the manuscript have been amalgamated. This section is divided into three main subsections, which align with the study aims stated above, and a fourth subsection that discusses the implications of these results for sport psychologists. To aid understanding, important sections of Vlad's interview are included in the text and further brief illustrative examples from his quotes are also included in brackets where relevant. Throughout the discussion, reversal theory concepts are used as a basis for interpreting and explaining Vlad's interview statements.

\section{Risk Perceptions and General Motivational Experience of Skydiving}

Vlad did not view skydiving as a risky or dangerous activity:

I don't think skydiving is a dangerous sport and if it was really, really dangerous I don't think I would be doing it.... It is extreme sport definitely but, there are so many rules.... and if you obey everything, it's a safe sport. It's like anything - if you've got the skills.

Even with his depth of experience, Vlad maintained his concern for skydiving safety rules and continuously monitored weather conditions:

... I wake up and check conditions...A Are they too dangerous? Not dangerous?... Assess conditions nonstop... At 20,000 jumps you are on a completely different level but you still go through the same things.

Krein (2007) maintained that most adventure sport participants put extensive effort into limiting the risks of their activities by, for example, using safe equipment or developing their knowledge and skills. Vlad used both of these strategies, thus his skydiving was not perceived as reckless risk-taking, but rather an adventure sport in which he took carefully appraised risks. A primary motive for Vlad's involvement in skydiving was achieving personal goals, as illustrated by this interview quote:

... you want to do it because you have fun, because you achieve something; you achieved what you wanted to achieve. So there is always a goal, there is definitely always a goal. We jump for fun sometimes when we don't work... and I always say I never jump for fun, I always jump... to learn something new. So I wouldn't say that I would do it just for the sake of doing it... you always have some goal.
This represents Vlad's telic (serious)-mastery motivation. His reward stemmed from postjump satisfaction associated with achieving his goals for that particular jump, or series of jumps on a certain day. A further indication of Vlad's telic-oriented motivation was his focus on planning ahead:

[I] focus on the future and planning ahead in every single jump... especially with these emergency procedures... every jump you have to concentrate on that and focus on the future, planning ahead, so you know what to do if this happens, you know what to do if that happens.

In addition to the telic (serious) motives reported by Vlad, his experience and emotions were also strongly influenced by mastery motivation as he worked to maintain control over his skydives and master the necessary skills:

You know and some days...I feel that I have under control every single second of my skydive and every single second of the landing. Or every single step of the landing, and I can feel that I can do really whatever I want to do with the canopy and I can land any way I want.

If you want to enjoy skydiving... you have to get good enough. You have to get to a level where you can actually enjoy it...Actually, training is part as well... the fact that every time you can do more things, you can have more control, you can learn more tricks - that's good fun.

In summary, Vlad's general motivational approach to skydiving was dominated by telic-mastery motivation, as exemplified by his focus on control and developing his skydiving skills (e.g., "you can have more control, you can learn more tricks - that's good fun"). His perceptions of mastery and control when skydiving were the most enjoyable aspects of the activity for him. In addition, the conformity and autic (self-oriented) states played a role in his motivational approach to skydiving, but these were less salient than the telic and mastery states. The conformist state was illustrated by Vlad's desire to obey safety rules, while his desire to achieve his own personal goals typified the autic state. Given the salience of telicmastery motivational states driving Vlad's skydiving, it was not surprising that Vlad never described feeling of excitement in connection with skydiving during his interview. Excitement is a pleasant emotion associated with the paratelic (playful) state. This is one of the most noteworthy findings in this case as it counters much of the adventure motivation literature (e.g., Chirivella \& Martinez, 1994; Hymbaugh \& Garrett; 1974; Rowland et al., 1986), including skydiving-specific research. For example, Apter and Batler (1997) found that excitement or thrill was the most highly rated motive for skydiving participation, while Kerr's (2007) case study of a female skydiver reported the importance of paratelic (playful) 
and negativistic (rebellious) motivational states. These findings are supported by the common assumption is that the pleasant "thrill" or increase in arousal experienced by adventure participants is caused by the release of adrenaline in their bodies ; participants often use the expression "adrenaline rush" when discussing their adventure experiences (Brymer et al., 2010). However, the present authors are unaware of research empirically linking increased physiological arousal with adrenaline release.

For Vlad, an "adrenaline rush" did not appear to be associated with thrills, but rather with "actually doing things right" when dealing with new maneuvers or emergency procedures (e.g., "When something goes wrong, my adrenaline goes through the roof straight away"; "Every time I was doing these [new] jumps I felt - not nervous - but my adrenaline would go up because it's a new thing"; "You do get that adrenaline rush, but it's different [than a thrill]"). During these new maneuvers or emergency procedures, Vlad felt "good, calm, happy and relaxed". His statements support Brymer's (2010) findings from research with extreme sport participants. Specifically, the base-jumper and climber in Brymer's study denied experiencing a thrill-based adrenaline rush during their activities and instead described it as a heightened state of relaxation characterized by mental and emotional clarity. Vlad's calm, and composed mental state, during which he felt happy when he coped successfully with complex task demands, typifies telic-mastery motivation as defined in reversal theory. In the telic motivational state, low arousal levels are experienced as pleasant and high arousal levels are unpleasant.

\section{Accepting New Challenges and Learning New Skills}

Vlad had been skydiving for 21 years and it appeared that his strategy for maintaining interest was to periodically take on new challenges, which required the learning of new skills to regain mastery and control over his adventure sport environment. This was a critical element in Vlad's motivation to participate in skydiving. His interview statements were unequivocal on this point (e.g., "Every time you wanna do something new it's actually a challenge"; "It's all about challenges so you always set up challenges . .."; "I never jump for fun; I always jump to learn something new"). These quotes and the following statement illustrate the strong role that his motivation to learn and develop new skills played in his enjoyment of skydiving:

when you're learning new things ... it's harder, but once you pass that stage and once you learn enough to be able to do new things... you have enough experience and skills to actually do new things. Then your jumps get really enjoyable.

Sometimes these "challenges" took the form of learning formation jumps or new styles and were often the result of the innovations in equipment or competitions. For example, Vlad described how the development of smaller canopies had resulted in competitions focused on the accuracy of skydivers' landings:

The canopies are getting smaller and faster - there are lots of new competitions that started a few years ago. So once you open the parachute the challenge is actually to learn to control your canopy to have perfect landings - really good long swoops...... With round canopies you're actually just touching the ground and that's it - you just land.

Trying to achieve perfect landings was an inviting challenge for Vlad because to do so he had to exert complete control over his canopy. The ability to exert this control satisfied his telic-mastery-oriented motivation.

Vlad's Experience of Learning Sky Surfing. Vlad's motivation to overcome challenges and master new skills was also shown by his decision to become competent in sky surfing. His detailed descriptions of his attempts to learn sky surfing provided particularly useful insights into how he dealt with a completely novel challenges and the progressive steps he took to gain proficiency in new techniques. Sky surfing is a skydiving technique in which the skydiver exits the plane with a snowboardsize board strapped to his or her feet. During the descent surfing-style maneuvers, such as balancing on the board and performing different loops and spins, are performed by the skydiver:

... now jumping with that sky surf board is pretty big as well there are lots of people competing in this branch of skydiving and I watched these guys. I watch the videos and they can do some amazing things - some really fast things and do some tricks, tracking, moving forward and things like that. So, I just wanted to be able to do that as well - I just wanted to do it! And so I started jumping, practising and that was my goal just to - not to be of course good enough to compete, but just to be able to do it.

Although some observers might infer that Vlad's continued desire to push himself and learn new skills involved seeking higher levels of danger or risk, his interview statements did not reflect this. On the contrary, he was totally focused on learning the new activity and never reported additional levels of risk or an added sense of danger during new challenges. His descriptions of learning to sky surf reflect this singular focus. As Vlad had no previous instruction in sky surfing, his first attempt involved basic trial and error learning. It was a "failure" and he was left feeling frustrated after the event:

I had no idea what to expect, I had no idea what to do. I just saw some videos of other people doing it - there was no one that could give me any tips or tell me how to do it so I jumped out and I could not get stable. I was just spinning and I had no idea what to do with it [the board]. I opened the parachute and I actually had to cut away that board, I had to get rid of the board. . . I l land and my whole body's 
aching - every muscle in my body was so sore you know (smiling)... I I landed after the jump and I felt very frustrated you know because I didn't do what I wanted to do ... of course I did expect that things wouldn't go the way I'd planned them to go, but you still feel very frustrated.

Goal achievement and planning ahead are characteristic of the telic state and Vlad's frustration at this point arose from his inability to achieve any of the skills necessary on the way to achieving his goal of sky surfing. After watching the sky surfing videos again, Vlad attempted further jumps and was more successful each time:

... so I jump again and I nearly managed to get up on the board. The point is you can actually stand up on the board and then it gets a little bit easier and then you can control it... and so the second jump wasn't good but it was better than the first. . . . when I did my third jump and I managed to get up on the board and I felt like I'm standing on top of the world. [It's] like the floor underneath me and I can see the mountains and lake and everything and it was so beautiful.

Before one particular jump, some ground work in which he simulated the necessary movements proved to be beneficial and reinforced his desire to sky surf:

Now for that particular jump I remember even before the jump I remember practising on the ground. I put the board on my feet and my parachute and everything so I was laying sort of on my back and laying with the board attached to my feet. I had my legs up in the air and I' $m$ holding the board and it felt like it's gonna be easy and I felt like 'wow, this is what I want to do, this is great.

Although he eventually achieved his telic-mastery goal of learning to sky surf successfully, almost immediately he embarked on a new challenge by using a bigger board and increasing the difficulty of the activity:

. . . again I remember a jump when I knew exactly what I'm gonna do, how I'm gonna do that and I jumped out with a new, much bigger board and I felt like I had everything under control. It felt so easy - I got up on the board, I managed to do a few tricks, turns, spins and things like that and it just felt so good. I opened the parachute and I land and I felt so good not just that day, but [for a] few days after.

Vlad's sky surfing experiences epitomise his general pattern of setting new challenges and learning new skills during his long skydiving career. It is also noteworthy that after watching videos of others skydiving he felt confident enough to try the technique himself. This suggests that Vlad understood his own skydiving abilities and determined that he had the capability to set his goal of learning to sky surf, take on this challenge, and achieve it. Willig (2008) found similar results with her sample of extreme sport participants. She pointed out that, although the participants wanted to push their personal boundaries through new challenges, they took care to ensure that the goals they set themselves were achievable. In addition, Willig (2008) reported that acquiring new technical knowledge and skills, and gaining experience, produced a rewarding sense of mastery for her participants. This was mirrored in Vlad's sky surfing experience (e.g., "I got up on the board, I managed to do a few tricks, turns, spins and things like that and it just felt so good"; "I felt so good not just that day, but [for a] few days after."). This feeling of mastery after taking on a new challenge appeared to be a key element in maintaining his motivation and interest in the sport.

\section{Mastery State Motivation and Confidence Frames}

In reversal theory terms, Vlad's perception of skydiving as a safe sport, was only possible through a protective confidence frame (or "psychological bubble") that he had 'built' around the activity. This frame was based on his experience and confidence in his abilities to do the right things, even in an emergency situation:

The whole day you're jumping and you don't feel anything, you don't feel anything - it's normal day and then you open the parachute and you notice like - instantly [snaps fingers] you notice something is wrong with your main canopy. Adrenaline goes up in a second - like crazy. ... And you don't even notice that, you know you just function - you do things you learned to do - you deal with the situation, but once you land and ... few minutes after that you notice how much your body's sort of tensed you know. And how much your brain is just working in full alert [laughs].

Similar statements throughout Vlad's interview confirmed the importance of the mastery state in emergency situations, such as this example of a defective main canopy. A sudden change in the skydiving environment can mean that the skydiver's confidence frame is lost. According to Apter (1992), loss of a confidence frame is caused by a reversal from the paratelic (playful) to the telic (serious) state. However, Males (2013) studying elite-level athletes showed that the confidence frame is more likely to be a function of the mastery state. This suggests that a decrease in the salience of the mastery state, or a mastery to sympathy state reversal as a result of environmental events, frustration or satiation, might be the stimulus needed for the confidence frame to fail. There is no evidence in Vlad's statement above indicative of him being in the paratelic (playful) state, or of a paratelic (playful) to telic (serious) state reversal and a failure of his confidence frame. Although Vlad's arousal (adrenaline) increased in this emergency situation, he functioned appropriately, dealt with the situation, and landed safely. It seems likely that Vlad was in the telic (serious) and mastery states during this experience 
and maintained his confidence frame throughout. This interpretation is supported by the noticeable absence of paratelic (playful) motives reported in Vlad's interview statements in general, and by his observation that "few minutes after that you notice how much your body's sort of tensed". Increased muscle tension has been associated with high levels of arousal in the telic (serious), but not the paratelic (playful) state (e.g., Svebak, 1991).

An additional statement from Vlad's interview indicated that the telic and mastery states were operative during his skydiving. On the few occasions when he felt scared (telic (serious) state with unpleasant high arousal), Vlad had developed a positive internal dialogue and visualization strategy for changing his mental state:

As soon as I feel scared, I convince myself this is what I want to do and it makes it so much easier. I visualise the entire jump and talk through the whole jump out loud. If I have confidence, I know I will perform well. I have to feel I want to do it.

Using mental strategies is one of the recognized ways of self-inducing motivational reversals ("Eight ways", 2003). Without being consciously aware of what he was doing, or briefed in reversal theory, Vlad used mental strategies (visualization and self-talk) to reestablish his desired state of mind. In reversal theory terms, Vlad used mental strategies to reinstate the telic (serious) and mastery states which allowed a robust confidence frame to be rebuilt. This increased Vlad's confidence, induced a reappraisal of the risks involved in his skydiving session, and dissipated feelings of fear. In his statement, there is no suggestion of a telic (serious) to paratelic (playful) reversal, which would result in reinterpretation of unpleasant high arousal in the telic (serious) state (feeling scared) as pleasant excitement in the paratelic (playful) state (Apter, 1992). In line with Males' (2013) findings, the current case indicates that Vlad's confidence frame was based on a telic (serious)-mastery state combination. The results of these two studies expand previous reversal theorist conjectures about the nature of protective confidence frames. However, further research in other adventure sports and high-risk activities is needed to validate and refine these developments.

\section{Implications for Sport Psychologists}

One well-established view in the sport psychology literature is that skydivers and other adventure sport participants take part because they are arousal seekers participating for the resultant excitement and thrill (adrenaline rush; e.g., Chirivella \& Martinez, 1994; Rowland, Franken, \& Harrison, 1986). Recent research and the current case study suggest that there are multiple motives for participation in adventure sports (e.g., Kerr \& Houge Mackenzie, 2012). Thus, sport psychologists should explore the broader range of participation motives identified here across individuals and adventure sports. Although the typical notion of high arousal enjoyment or an 'adrenaline rush' in adventure activities is important for those whose operative metamotivational states are paratelic-mastery, the current case study demonstrates that telic-mastery-oriented participants will interpret high arousal levels very differently. Vlad's continued participation in skydiving was carefully managed using new self-determined, achievable challenges that satisfied his telic-mastery needs when the new skills were mastered. Thus, different combinations of metamotivational states give rise to different needs and motives for skydiving participation that extend beyond mere excitement-seeking. In motivational terms, "one size fits all" is unacceptable in reversal theory and when explaining skydiving behavior (Apter \& Batler, 1997).

This case study is also relevant to sport psychologists interested in the motivational processes involved in skydiving in particular. This case demonstrates that participants may enjoy skydiving when they understand the risks involved, but feel confident and secure enough to perceive these risks as manageable. Their confidence may be based on factors such as personal knowledge of the sport and their ability to perform necessary skills, sometimes under difficult circumstances. If skydivers are in situations where they are dependent on other team members, they must also be confident about the competency of their colleagues. Confidence is also created by having safe, technologically-advanced equipment that they know has been well-tested and can withstand the demands of their sport. In reversal theory, high levels of confidence produce positive emotions through the creation of a protective confidence frame. Whereas most people would be afraid to launch themselves from an aircraft in flight, skydivers generally enjoy exiting aircrafts at heights of $3-4,500 \mathrm{~m}$. As even strong confidence frames sometimes fail it is useful for psychologists to understand the motivational processes involved in skydiving so that they can assist participants whose confidence frames have dissolved. Kerr (2007) has discussed some of the options available for intervention in the case of a participant who has experienced a huge loss of confidence and associated paratelic protective frame. Similarily, intervention options may need to be developed for skydivers who lose their telic-masterybased protective frames.

\section{Conclusions and Future Study}

There have been relatively few qualitative studies on the experience of motivation in skydiving informed by reversal theory. The interview material reported in the present case study provided rich, in-depth, dynamic, and complex representations of an elite male skydiver's motivational experience. As such, it was a unique case study that contributed original findings which challenged reversal theory's concept of paratelic-oriented (i.e., thrills and excitement) protective confidence frames in skydiving and possibly other adventure sports. The association between frames and telic-mastery motivations should be recognized within reversal theory and further researched in the future. Case study findings should not be used as a 
basis for generalization in the traditional sense of the term in the social sciences (Flyvbjerg, 2006). Rather, the present findings can act as a basis for a working hypothesis, providing a means of facilitating learning and naturalistic generalization (Lincoln \& Guba, 1985; Skate, 1995), used toward a greater understanding of adventure sport participation motivation. For comparison with the present case study, further case study research could investigate motivational experience (operative motivational states, emotions, and factors influencing protective confidence frames) in other expert skydivers (including expert female skydivers) and/or expert performers across a broader range of adventure activities. Examining the skydiving experience exclusively from the perspective of reversal theory may have limited other interpretations of the data. However, using reversal theory did provide a meaningful explanation of how accepting renewed challenges and learning new skills played an important role in maintaining the participant's ongoing motivation and confirmed the possibility of mastery-based confidence frames in motivational experience.

\section{References}

Allman, T.L., Mittelstaedt, R., Martin, B., \& Goldenberg, M. (2009). Exploring the motivations of base jumpers: Extreme sport enthusiasts. Journal of Sport \& Tourism, 14, 229-247. doi:10.1080/14775080903453740

Apter, M.J. (1982). The experience of motivation. London, England: Academic Press.

Apter, M.J. (1992). The dangerous edge. New York, NY: Free Press.

Apter, M.J. (1993). Phenomenological frames and the paradoxes of experience. In J.H. Kerr, S. Murgatroyd, \& M.J. Apter (Eds.), Advances in reversal theory (pp. 27-39). Amsterdam, The Netherlands: Swets \& Zeitlinger.

Apter, M.J. (2001). Motivational styles in everyday life: A guide to reversal theory. Washington, DC: American Psychological Association.

Apter, M.J., \& Batler, R. (1997). Gratuitous risk: A study of parachuting. In S. Svebak \& M.J. Apter (Eds.), Stress and health: A reversal theory perspective. Washington, DC: Taylor \& Francis.

Bromley, D.B. (1986). The case-study method in psychology and related disciplines. Chichester, England: John Wiley.

Brymer, E. (2009). Extreme Sports as a facilitator of ecocentricity and positive life changes. World Leisure Journal, 51, 47-53. doi:10.1080/04419057.2009.9674581

Brymer, E. (2010). Risk taking in Extreme sports: A phenomenological perspective. Annals of Leisure Research, 218-239.

Brymer, E., Downey, G., \& Gray, T. (2009). Extreme sports as a precursor to environmental sustainability. Journal of Sport \& Tourism, 14, 193-204. doi:10.1080/14775080902965223

Brymer, E., \& Gray, T. (2010). Developing an intimate "relationship" with nature through extreme sports participation, Leisure/Loisir, 34, 361-374

Brymer, E., \& Oades, L.G. (2009). Extreme sports: A positive transformation in courage and humility.
Journal of Humanistic Psychology, 49, 114-126. doi:10.1177/0022167808326199

Burke, S., \& Orlick, T. (2003). Mental strategies of elite Mount Everest climbers. Journal of Excellence, 8, 42-58 Retrieved from http://www.zoneofexcellence.ca/free/ excellence/02_Mental_Strategies.pdf.

Chirivella, E.C., \& Martinez, L.M. (1994). The sensation of risk and motivational tendencies in sports: An empirical study. Personality and Individual Differences, 16, 777-786. doi:10.1016/0191-8869(94)90219-4

Cogan, N.A., \& Brown, R.I.F. (1999). Metamotivational dominance, states and injuries in risk and safe sports. Personality and Individual Differences, 27, 503-518. doi:10.1016/ S0191-8869(98)00259-1

Denzin, N.K., \& Lincoln, Y.S. (Eds.). (2000). Handbook of qualitative research ( 2 nd ed.). Thousand Oaks, CA: Sage. (2003). Eight ways of being. Loughborough, England: Apter International Ltd.

Florenthal, B., \& Shoham, A. (2001). The impact of persuasive information on changes in attitude and behavioural intentions toward risky sports for arousal-seeking versus arousal-avoiding individuals. Sport Marketing Monthly, $10,83-95$.

Flyvbjerg, B. (2006). Five misunderstandings about casestudy research. Qualitative Inquiry, 12(2), 219-245. doi: $10.1177 / 1077800405284363$

Gratton, C., \& Jones, I. (2004). Research methods for sport studies. New York, NY: Routledge.

Hanton, S. (Ed.). (2012). Case studies in sport psychology [Special Issue]. The Sport Psychologist, 26, 483-643.

Houge, S.P. (2009). Reversal theory and flow: Toward an integrated framework of optimal experiences in adventure activities. Unpublished Ph.D. thesis, School of Physical Education. University of Otago, Dunedin, New Zealand.

Houge Mackenzie, S., Hodge, K., \& Boyes, M. (2011). Expanding the flow model in adventure activities: A reversal theory perspective. Journal of Leisure Research, 43(4), 519-544.

Houge Mackenzie, S., Hodge, K., \& Boyes, M. (2013). The multi-phasic and dynamic nature of flow in adventure experiences. Journal of Leisure Research, 45(2), 214-232.

Houge Mackenzie, S., \& Kerr, J.H. (2012). A (mis)guided adventure tourism experience: An autoethnographic analysis of mountaineering in Bolivia. Journal of Sport \& Tourism, 17, 125-144. doi:10.1080/14775085.2012.729901

Hymbaugh, K., \& Garrett, J. (1974). Sensation-seeking among skydivers. Perceptual and Motor Skills, 38, 118. PubMed doi: 10.2466/pms.1974.38.1.118

Jackson, S.A. (1996). Toward a conceptual understanding of the flow experience in elite athletes. Research Quarterly for Exercise and Sport, 67(1), 76. PubMed doi:10.1080/0 2701367.1996.10607928

Kerr, J.H. (1991). Arousal-seeking in risk sport participants. Personality and Individual Differences, 12(6), 613-616. doi:10.1016/0191-8869(91)90258-D

Kerr, J.H. (2007). Sudden withdrawal from skydiving: A case study informed by reversal theory's concept of protective frames. Journal of Applied Sport Psychology, 19, 337-351. doi:10.1080/10413200701342699 
Kerr, J.H., \& Houge Mackenzie, S. (2012). Multiple motives for participating in adventure sports. Psychology of Sport and Exercise, 13, 649-657. doi:10.1016/j.psychsport.2012.04.002

Kerr, J.H., \& Svebak, S. (1989). Motivational aspects of preference for and participation in risk sports. Personality and Individual Differences, 10, 797-800. doi:10.1016/0191-8869(89)90127-X

Krane, V., Andersen, M.B., \& Strean, W.B. (1997). Issues of qualitative research methods and presentation. Journal of Sport \& Exercise Psychology, 19, 213-218.

Krein, K. (2007). Nature and risk in adventure sports. In M.J. McNamee (Ed.), Philosophy, risk and adventure sports (pp. 80-93). London, England: Routledge.

Legrand, F.D., \& Apter, M.J. (2004). Why do people perform thrilling activities? A study based on reversal theory. Psychological Reports, 94, 307-313. PubMed doi:10.2466/ pr0.94.1.307-313

Lincoln, Y.S., \& Guba, E.G. (1985). Naturalistic inquiry. Newberry Park, CA: Sage.

Lipscombe, N. (1999). The relevance of the peak experience to continued skydiving participation: A qualitative approach to assessing motivations. Leisure Studies, 18, 267-288. doi:10.1080/026143699374853

Lonsdale, C., Hodge, K., \& Raedeke, T. (2007). Athlete engagement: I. A qualitative investigation of relevance and dimensions. International Journal of Sport Psychology, 38, 451-470.

Males, J. (1999). Individual experience in slalom canoeing. In J.H. Kerr (Ed.), Experiencing sport: Reversal theory (pp. 101-128). New York, NY: John Wiley \& Sons.

Males, J.R. (2013). A reversal theory model of sport performance. Unpublished Ph.D. thesis, Department of Sport and Exercise Sciences, University of Aberysthwyth, Aberystwyth, Wales, United Kingdom.

Males, J.R., Kerr, J.H., \& Gerkovich, M.M. (1998). Metamotivational states during canoe slalom competition: A qualitative analysis using reversal theory. Journal of Applied Sport Psychology, 10, 185-200. doi:10.1080/10413209808406387

O'Connell, K.A., Potocky, M., Cook, M.R., \& Gerkovich, M.M. (1991). Metamotivational state interview and coding schedule instruction manual. Kansas City, MO: Midwest Research Institute.

Pain, M., \& Kerr, J.H. (2004). Extreme risk taker who wants to continue taking part in high risk sports after serious injury. British Journal of Sports Medicine, 38, 337-339. PubMed doi:10.1136/bjsm.2002.003111

Patton, M.Q. (2002). Qualitative research and evaluation methods (3rd ed.). London, England: Sage.
Potocky, M., Gerkovich, M.M., O’Connell, K.A., \& Cook, M.R. (1991). State-outcome consistency in smoking relapse crises: A reversal theory approach. Journal of Consulting and Clinical Psychology, 59, 351-353. PubMed doi: $10.1037 / 0022-006 X .59 .2 .351$

Richardson, J.T.E. (Ed.). (1996). Handbook of qualitative research methods for psychology and the social sciences. Leicester, England: The British Psychological Society.

Rowland, G.L., Franken, R.E., \& Harrison, K. (1986). Sensation seeking and participation in sporting activities. Journal of Sport Psychology, 8, 212-220.

Scanlan, T.K., Russell, D.G., Beals, K.P., \& Scanlan, L.A. (2003). Project on elite athlete commitment (PEAK): II. A direct test and expansion of the Sport Commitment Model with elite amateur sportsmen. Journal of Sport \& Exercise Psychology, 25(3), 377-401.

Scanlan, T.K., Russell, D.G., Wilson, N.C., \& Scanlan, L.A. (2003). Project on elite athlete commitment (PEAK): I. Introduction and methodology. Journal of Sport \& Exercise Psychology, 25, 360-376.

Skate, R.E. (1995). The art of case study research. Thousand Oaks, CA: Sage.

Svebak, S. (1991). One state's agony, the other's delight. Perspectives on coping and musculoskeletal complaints. In C.D. Spielberger, I.G. Sarason, J. Strelau, \& J.M.T. Brebner (Eds.), Stress and anxiety (Vol. 13, pp. 215-229). New York, NY: Hemisphere.

Thatcher, J., Reeves, S., Dorling, D., \& Palmer, A. (2003). Motivation, stress and cortisol responses in skydiving. Perceptual and Motor Skills, 97, 995-1002. PubMed doi:10.2466/pms.2003.97.3.995

Trimpop, R.M. (1994). The psychology of risk-taking behaviour. Amsterdam, The Netherlands: North Holland.

Trimpop, R.M., Kirkcaldy, B., \& Kerr, J.H. (1998). Comparing personality constructs of risk-taking behavior. Personality and Individual Differences, 26, 237-254. doi:10.1016/ S0191-8869(98)00048-8

Varley, P.J. (2011). Sea Kayakers at the margins: The liminoid character of contemporary adventures. Leisure Studies, 30, 85-98. doi:10.1080/02614361003749801

Wheaton, B. (2004). Mapping the lifestyle sport-scape. In B. Wheaton (Ed.), Understanding lifestyle sports (pp. 1-28). London, England: Routledge.

Willig, C. (2008). A phenomenological investigation of the experience of taking part in extreme sport. Journal of Health Psychology, 13, 690-702. PubMed doi: $10.1177 / 1359105307082459$

Yin, R.K. (1994). Case study research: Design and methods. London, England: Sage. 